\title{
Creating Safe Schools: The Importance of Peers in Bully Prevention Programs
}

\author{
Lori A. Smolleck, Ph.D. \\ Chair, Department of Education, Bucknell University \\ Associate Professor of Education \\ Sarah Fryd, Psy.D. \\ School Psychologist, \\ John Jay Middle School
}

\begin{abstract}
The purpose of this study was to review the existing literature on bullying and investigate prevention programs currently in existence. Furthermore, this research examined the Creating a Safe School (CASS) program used within a middle school in Central Pennsylvania. Because CASS utilizes peer mentors and educators, this study also examined the importance of peers in adolescent's lives and the importance of using peers as a way to create safe schools. Methods for constructing effective and efficient bullying prevention programs are discussed using the data analysis, as well as current research in the field. The overall aim of this research study is to lead educators, administrators, parents, and other individuals working with children and adolescents toward a better understanding of the various types of bullying, how and why bullying occurs, as well as how bullying can be addressed and prevented.
\end{abstract}

Key Words: Bullying, Bullying Prevention, Relational Aggression, Cyberbullying, Peer Mentoring

\section{INTRODUCTION AND RATIONALE}

Schoolyard bullying, defined as a "behavior...intended to harm or disturb...occur[ing] repeatedly over time" in which "there is an imbalance of power, with a more powerful person or group attacking a less powerful one" has long been a part of childhood and adolescence (Nansel et al., 2001, p. 2094). Although bullying been around for quite some time, the recent suicides and school violence caused by bullying illustrate that it is not an issue that should be ignored, nor should it be blindly accepted as a normal part of life. Because of its pervasiveness and potentially devastating consequences, bullying has recently become the subject of much research aimed at examining what exactly bullying is, its prevalence, who it affects, and its impact on both the perpetrator and the victim.

Much of the initial research on bullying was conducted in Scandinavia, but researchers have now begun to study it more in other countries, including the United States, where bullying seems to be extremely prevalent. Guerra, Williams, \& Sadek (2011) found "prevalence rates for...self-reported bullying...in elementary, middle, and high school" to be " $50 \%$, $71 \%$, and $72 \%$, respectively" (p. 300). These rates, especially in middle and high school, are remarkably high, and still there is reason to believe they will continue to increase. Due to the advancement of technology, the home no longer provides a safe haven for adolescents, a place for them to escape the bullying. With the increasing popularity of technology such as the internet, a new type of bullying has emerged called cyberbullying, in which the adolescent is "tormented, 
threatened, harassed...or otherwise targeted by another child using the Internet, interactive and digital technologies or mobile phones" (WiredKids, n.d.).

Given the prevalence of bullying and the negative consequences associated with it, there have been many prevention programs tested and implemented in different schools. Olweus' Bullying Prevention Program (1993) was the first and largest of such programs, aiming to address "bullying at multiple levels - the entire school, the classroom, and the individual" (Bauman, 2008, p. 366). Since then, numerous other programs have evolved, and have been implemented with varying degrees of success. As such, the aim of the research was to review the existing literature on bullying and investigate the numerous prevention programs in existence. This research also purported to detail and evaluate one specific bullying prevention program, called Creating A Safe School (CASS), which is used at a Middle School in Central Pennsylvania. (This particular middle school will be referred to as "Central Area Middle School" throughout this article). CASS uses the school counselor as its leader, however it also utilizes students themselves as peer mentors. Because of this, the present research also examined the importance of peers in adolescent's lives, and the rationale for using peers as mentors and educators.

\section{Bullying}

\section{REVIEW OF LITERATURE}

As discussed above, bullying is exposure, "repeatedly and over time, to negative actions on the part of one or more other students" (Olweus, 1995, p. 197). These "negative actions" vary greatly, and thus there are several different types of bullying, including physical, verbal, social (spreading rumors about someone or trying to hurt their status within a group), psychological (threatening or manipulating someone), and cyberbullying, in which adolescents use technology as another medium through which to carry out their aggression (Carr-Gregg \& Manocha, 2011). Several studies have found that males are more likely to be involved with bullying, both as perpetrators and victims (Nishina, Juvonen, \& Witkow, 2005; Seals \& Young, 2003; Pepler, Craig, Jiang, \& Connolly, 2008), but it is quite plausible that these studies simply focused more on the overt types of bullying, such as physical and verbal, and less on the covert types of social and psychological. Crick \& Grotpeter (1995), indeed, found that girls were more relationally aggressive (which includes both social and psychological) than boys were. In a survey of 9-12 year-olds, Crick, Bigbee, \& Howes (1996) found that relational aggression was the most frequently reported aggressive behavior used for girls, while physical aggression was the most common for boys.

\section{Prevalence}

The rates of youth's experience with bullying vary from study to study, ranging anywhere from $20 \%$ (when bullying is described as occurring at least once a week) to an astounding $72 \%$ (when bullying is described as occurring at any time throughout one's schooling), with moderate rates of bullying found in about 30\% of students (Seals \& Young, 2003; Guerra, Williams, \& Sadek, 2011; Nansel et al., 2001). Though exact rates of bullying are unknown and vary, there is reason to believe that the prevalence is increasing. In a 2001 study, it was found that "children aged 8-15 years rate[d] bullying as a greater problem than racism or peer pressure to have sex or use alcohol and other drugs" (as cited in Carr-Gregg \& Manocha, 2011, p. 98). Also, with the increasing usage of technology, especially among adolescents, there is reason to believe that rates of bullying are even higher, as the internet provides aggressors with another medium through which to bully. In her book Odd Girl Out, Rachel Simmons (2011) devotes a chapter to cyberbullying, and though she discusses it in terms of female aggression only, she cites studies that prove that males are affected by cyberbullying, as well. Simmons discusses one specific website, Formspring.me, in which users create profiles, on 
which their peers can post comments and answer the question "what do you think about me?" anonymously. Unfortunately, this anonymity often encourages users to post mean and hurtful comments, such as saying that the user is ugly, or that the user should go die (Simmons, 2011). To further prove that technology lends itself to bullying, the Youth Internet Safety Surveys, carried out in 2000 and 2005, found an increase in youth's (ages 10-17) experience with online harassment in the 2005 survey, both as perpetrators and victims (Mitchell, Wolak, \& Finkelhor, 2007).

\section{Impact}

In examining bullying and its occurrence, it is important to look at who the perpetrators and victims are, and the effects associated with carrying out bullying, being bullied, or sometimes both. Several studies have found that bullies have more school adjustment difficulties, in that they both perceive school to be more negative and have lower academic competence (Coie, Lochman, Terry, \& Hyman, 1992; Nansel et al., 2001; Mynard \& Joseph, 1997). Haynie et al. (2001) aimed to look at the distinct profiles of different groups involved with bullying and found that perpetrators of bullying had lower "psychosocial functioning... self-control and...social competence" and more "problem behaviors such as drinking, smoking, theft, damage to property, and violations of parents' rules" (p. 44). They were also found to have more "deviant peer" groups (p. 44). This finding is further supported by Pepler, Craig, Jiang, \& Connolly (2008), who reported that bullies lacked supportive friend groups and instead befriended other perpetrators of bullying. These researchers also found in their longitudinal study that moderate perpetrators of bullying were more likely to come from divorced families, and that they were also more likely to lack supportive family relationships and receive less parental monitoring (2008). The research on bullies' self-esteem is less conclusive, as some studies have found that bullies tended to have higher self-esteem and were more popular (Seals \& Young, 2003), while others have found that bullies tended to have lower self-esteem, for which it was hypothesized that they bullied so that other people would feel as badly as they did (Guerra, Williams, \& Sadek, 2011).

With regard to self-esteem for victims of bullying, Guerra, Williams, \& Sadek (2011) found that having low self-esteem was actually "the most robust predictor of victimization," and wasn't just a consequence of having been bullied. Nansel et al. (2001) identified other risk factors for being bullied as being "socially isolated and lack[ing] social skills," (p. 2098) and found that being bullied was related to feelings of "increased loneliness" (p. 2097). In a longer study aiming to examine the effects of being a victim of bullying, students were surveyed in the fall and spring of the $6^{\text {th }}$ grade. It was found that having a higher perception of victimization (and presumably, a higher experience of victimization) in the fall of $6^{\text {th }}$ grade "significantly predicted higher levels of psychosocial problems...and physical symptoms...in spring of sixth grade" (Nishina, Juvonen, \& Witikow, 2005, p. 43). These psychosocial symptoms and physical symptoms also predicted school functioning, such that higher levels of these symptoms were related to a lower level of school functioning. The authors thus concluded that peer victimization indirectly effects school functioning. Similarly, Juvonen, Nishina, \& Graham (2000) studied a model that examined a similar link, hypothesizing that "higher levels of selfperceived victimization should predict poorer psychological adjustment, and this poor adjustment ought to [be the] determinant of problematic school outcomes" (p. 350). An analysis of 243 participants aged 12-15 confirmed this hypothesis. It is clear from these studies that being a victim of bullying takes a physical, psychosocial, and psychological toll on the individual, and that this can cause them to feel less safe at school and thus have a more negative school experience (Glew, Fan, Katon, Rivara, \& Kernic, 2005; Guerra, Williams, \& Sadek, 2011; Nishina, Juvonen, \& Witikow, 2005; Juvonen, Nishina, \& Graham, 2000). Because 
of the numerous damaging outcomes related with bullying, both as perpetrators and victims, the need for an effective prevention program becomes all the more clear.

\section{Prevention of Bullying}

It is evident, both from the prevalence of bullying, and the numerous negative outcomes related with bullying, that there is a definite need for effective prevention programs to be implemented in schools. As previously noted, the first and largest of such prevention programs was the Olweus' Bullying Prevention Program (1993), which was "conducted...in Bergen, Norway, in the early 1980s [and] addressed bullying at multiple levels - the entire school, the classroom, and the individual" (Bauman, 2008, p. 366). At the school level, Olweus (1993) proposed and implemented a school conference in which all staff and certain students and their parents attended, increased staff supervision of students, teacher-parent meetings, and the development of groups of teachers "to concentrate on various aspects of bullying" (p. 77). With regards to the classroom level, Olweus' program consisted of developing a set of rules in each class describing what bullying is and how to help someone who's been bullied, ensuring that there are consequences for someone who bullies another student, having class meetings that "allow...for discussions of bullying," and role-playing opportunities (p. 88). If, even with these measures in place, bullying did occur, Olweus' plan required having "serious talks with bullies and victims [and] with parents of involved students...help from 'neutral students'...help and support for parents," (p. 64), and ultimately, if nothing else worked, Olweus advised "distribut[ing] [the bully and victim] among different classes, or possibly even among different schools" (p. 106). After implementation in 42 schools, the program boasted a "reduction - by 50 percent or more - in bully/victim problems during the two years following the introduction of the intervention program" (p. 113) and a notable "increase in student satisfaction with school life" (p. 114).

While the original implementation of Olweus' program seems to have been quite effective, other schools have tried to replicate the program with mixed success. For example, Smith \& Ananiadou (2003) found that after implementation of the model in South Carolina schools, although there was a significant difference between the experimental schools (who received the Olweus intervention program) and control schools (who didn't receive the program) in the number of students who reported bullying other students, there was no significant difference in the self-reported victimization of students (as cited in Bauman, 2008, p. 366).

Another antibullying program, modeled after Olweus' program, is the Expect Respect Project, "an innovative violence prevention project funded by the Centers for Disease Control" (Meraviglia, Becker, Rosenbluth, Sanchez, \& Robertson, 2003, p. 1348). The program has "five components: classroom curriculum, staff training, policy development, parent education, and support services" (p. 1350), and was implemented in six elementary schools. After analyzing the distributed questionnaires, the researchers concluded that because students from the experimental schools reported significantly more bullying behaviors, the program "...increased students' and staff members' awareness of [such] behaviors" (p. 1355). It is also important to note that the students believed that if they told a teacher about bullying, the teacher would tell them to ignore it, whereas less than 7\% of staff approved of this response. In Bauman's (2008) review of this finding, she claims that this is pertinent to future antibullying programs, as it indicates that "one element of a successful program is convincing students that the adults are committed to action and trained to help" (p. 367). Although Meraviglia et al. (2003) found evidence for increased awareness of bullying, they found limited evidence for any effect on the actual occurrence of bullying. In an updated and adapted model of the Expect Respect Project, however, called the Steps to Respect intervention program, Frey, Edstrom, \& Hirschstein 
(2005) found "reductions in bullying, victimization, and destructive bystander behaviors" (as cited in Bauman, 2008, p. 367).

In her review of bullying prevention programs, Bauman (2008) synthesizes the results of Vreeman and Carroll's (2007) review of such programs, and claims that "whole-school approaches addressing the problem at a systemic level are most likely to have positive outcomes when the staff is committed and involved, and that interventions targeted at specific groups of children are most likely to reduce bullying with younger children" (p. 368). She also discusses the importance of having "an identified person in the school...take a leadership role," such as the school counselor, and then having that person develop a team of staff and parents to help understand and implement the program (p. 369).

In a quest to determine what else contributes to the success of antibullying programs, Smith, Cousins, \& Stewart (2005) sent surveys to the principals of Ontario schools to assess "characteristics of the school and the student body...nature and severity of bullying problems at the school...adequacy of resources directed at solving bullying...[and] current interventions and services in the school intended to deal with bullying and its effects" (p. 746). They looked at how dependent the impact of antibullying programs were on the "needs, resources, outputs, [and] activities" (p. 744) of the schools, and ultimately concluded that "the investment of time, effort, and money in school-based antibullying initiatives can yield valuable returns by helping to create school environments that are safer and more peaceful for children, and, by implication, more conducive for learning and healthy development" (p. 753). This finding, in addition to the success of the specific program models described above, and the recommendations for effective programs, indicate that there is clear evidence to support the notion that antibullying programs are essential and valuable to a school, and thus, to a child's safe and enjoyable experience with school.

\section{Importance of Peers}

According to Erik Erikson's theory of development, adolescents are at the critical period in which they are faced with the dilemma of identity vs. role confusion (1963). In this stage, they "are...concerned with what they appear to be in the eyes of others," are "eager to be affirmed by [their] peers, and [are] ready to be confirmed by rituals, creeds, and programs which at the same time define what is evil, uncanny, and inimical" (p. 261-263). If one takes Erikson's analysis of adolescence as fact, then, it is clear that peers have an enormous influence on the individual's healthy development, and that peers themselves can define what is normal and what is unacceptable. It also stands to reason that if one is rejected by his or her peers, he/she is more at risk for problem behaviors and other developmental consequences.

In a study designed to assess this risk of peer rejection, Newman, Lohman, \& Newman (2007) surveyed 733 students aged 11-18 about their "peer group membership" and "affiliation," "sense of peer group belonging," and "behavior problems" (p. 248). They found that subjects "report[ed] fewer internalizing and externalizing problems when they experience[d] a sense of group belonging" (p. 256), and also that those who said being a member of a group was important but reported not being a member of a group had significantly more "behavior problems" (p.248) than those who were members of a group. From this study, in conjunction with Erikson's description of the adolescent developmental stage, one can see the necessity of being part of a peer group, what might happen if one feels rejected by peers, and the importance of peers beliefs in determining what is acceptable and unacceptable behavior. 


\section{Peer Education}

The afore-mentioned study and Erikson's stage dilemma certainly provide evidence that peers are important to adolescents in their healthy development and their identity, thereby demonstrating the importance of peer education. Peer education typically involves "students delivering an educational programme who are of similar, or slightly older, age than the students receiving the programme" (Mellanby, Rees, \& Trip, 2000, p. 533). One theory that lends support to the idea of peer education is Bandura's social learning theory, which posits that individuals "observe behavior taking place and then go on to adopt similar behavior...depend[ing] on the characteristics of models" (as cited in Turner \& Shepherd, 1999, p. 237). With regards to peer education, the models in this case are the peer educators themselves, who should in theory be similar to those receiving the education. Similarity in age and in experience should cause the adolescents receiving the education to be more apt to listen to the educators and "adopt similar behaviors" to theirs (p. 237). Consequently, in an antibullying program when peer educators were used, the hope would be for them to model exemplary behavior, including standing up for victims of bullying and telling someone in charge, and for the individuals receiving the education to see them doing this and in turn, copy the behavior.

Another theory on which to justify peer education is Sutherland's Differential Association Theory. Sutherland "argued that...crime is learned behavior," and that "young people learn 'bad' habits...by associating with others who...teach them" (as cited in Turner \& Shepherd, 1999, p. 241-242). According to this theory, simply being around peers "provides a learning opportunity," (p. 242) and thus it is argued that if peers can influence one another to learn bad habits and behaviors, they should be able to influence them to learn good habits and behaviors, as well. It is likely that seeing bullying occur or being a victim influences adolescents to be perpetrators of bullying themselves, perpetuating the cycle. If, instead, they are taught by peer educators that bullying is not okay, and again, see these peer educators stand up for the victims and report the perpetrators, according to Differential Association Theory, the adolescents should learn this behavior and begin to stand up for the victim and report the bully, as well.

Based on these overarching theories, Turner \& Shepherd (1999) cite several justifications for using peer education found in the literature, including the ideas that "peer education is empowering for those involved...peers are more successful than professionals in passing on information because people identify with their peers...peer educators act as positive role models...[and] peer education can be used to educate those who are hard to reach through conventional methods" (as cited in Turner \& Shepherd, 1999, p. 236). In an effort to provide evidence for the success of peer education, Mellanby et al. looked at publications of studies involving health education and found "thirteen...detailing comparative trials of peer-led and adult-led education in schools...10 carried out in North America, one in Finland, one in Australia, and one an international collaboration" (p. 535). In twelve of the thirteen studies, they found that "peer-led students gained as much knowledge...or more than the adult led group," and that while "none of the studies reported that adults were more effective in altering attitudes [of participants,] three showed peers to be more effective" (p. 533). From this study, it can be concluded that peer education does not have a negative impact on educational programs. In fact, in most cases, peer education is found to be effective in conveying information and changing participants' opinions. There is reason to think, based on this study and the theories and justification of peer education, that an antibullying program using peer educators would thus be quite beneficial in changing the attitude towards and occurrence of bullying in schools. 


\section{Description of Program Model}

\section{PROGRAM MODEL}

As mentioned earlier, one example of a bullying prevention program is the Creating a Safe School (CASS) program, which is in effect at "Central Area Middle School", located in Central Pennsylvania. The program's basic roots and framework stem from the "Ophelia Project," (The Ophelia Project, 2006) which in 2002 conducted a workshop/training in "Central Area Middle School" about peer aggression, and implementing change in the school system. Participants of the workshop, including teachers, learning support staff, and other faculty members, created a vision about what a safe school climate meant to them, and a task force consisting of school counselors, administrators, community members, student representatives, and teachers was also formed to develop policies and guidelines to help ensure that the "Central Area Middle School" was a safe climate. The vision statement for the program, which is displayed in the school's cafeteria for the students to see each day is as follows:

"Our school community will seek to encourage and support a climate of acceptance and the celebration of individuality. The atmosphere will be one of trust, mutual respect, safety, and responsibility. Our environment will promote equally the emotional and academic development of all. These ideals will empower each member of the community to defend and nurture one another."

The policies that were developed by the taskforce and approved by the school board are now included in the "pupils" section of the school's handbook under the title "Bullying/Cyberbullying." Bullying is defined as "intentional electronic, written, verbal or physical act or series of acts directed at another student or students, which occurs in a school setting and/or outside a school setting, that is severe, persistent or persuasive" "Central Area Middle School", 2008). The policy goes on to describe that bullying should be reported and will then be investigated, and it details the consequences for perpetrators of bullying, which include "loss of school privileges...transfer to another school building, classroom or school bus...detention...suspension...counseling...[and possible] referral to law enforcement officials" (“Central Area Middle School”, 2008).

Although origination of CASS is in the Olphelia Project, many of the resources that CASS uses today are from Dr. Allan Beane's Bully Free Program (Beane, 2009). Like the Ophelia Project, Dr. Beane himself also came to "Central Area Middle School" in 2005 to conduct workshops for school personnel and presentations for students in grades 3-8 and their parents that focused on bullying itself, warning signs of bullying, and practical strategies to prevent and stop bullying. The Bully Free Program is "the most comprehensive school-wide (and system-wide) anti-bullying program" and "is based on research and includes administrative strategies, teacher strategies...student involvement, and bystander empowerment" (Bully Free Systems, 2012). In an evaluation of the effectiveness of this program in middle schools, Spurling (2006) found that the program "significantly decreased incidences of aggressive and violent behavior...increased the comfort level and confidence of personnel in their ability to deal with bullying...[and] increased a sense of security" (as cited in Bully Free Systems, 2012). Whereas the Ophelia Project focuses more on relational aggression and other non-physical types of bullying, the Bully Free Program focuses on bullying in a more general sense, and on empowering bystanders. The two programs therefore complement one another well, and thus there is reason to believe that CASS is likely effective, as the Bully Free Program was found to be quite effective alone, as cited above.

\section{Purpose of Creating a Safe School (CASS)}

The main purpose of Creating a Safe School is to help "Central Area Middle School" prevent bullying from occurring. Other, more specific goals of the program, as defined in the bylaws, 
are to educate members of the club about bullying, empower bystanders by providing them with knowledge about how to intervene when they see bullying happen, and to promote a sense of belonging and acceptance in all students.

\section{Participants}

Two guidance counselors at the "Central Area Middle School" formed CASS in 2008. One of these counselors now works at the Intermediate School, but the other, remains the guidance counselor at "Central Area Middle School", and is in charge of CASS. In addition to this guidance counselor, other members of the program are mentors, defined in the bylaws as "students trained in CASS Club principles and programs," and mentor facilitators, defined as "faculty, staff, or community members trained to coordinate and oversee CASS Club programs and mentors" ("Central Area Middle School", 2008). This past year, there were 67 mentors, and nine mentor facilitators, including the guidance counselor at "Central Area Middle School", and local college students.

The CASS mentors are primarily eighth graders, although in 2011 the program began opening up to a few select seventh graders, as well. The mentors are chosen based on an extensive screening process by the guidance counselor and other staff members at the school based on academic performance and attendance rates, discipline history, and teacher input regarding certain desirable characteristics, such as leadership and helpfulness. After being selected, the mentors must attend at least $70 \%$ of the CASS club bi-weekly meetings and activities, and maintain good academic standing and regular school attendance in order to remain in the club.

\section{Description}

\section{INTERVENTION PROGRAM}

One of the most notable aspects of the CASS program is the intervention program that the mentors and mentor facilitators deliver to the incoming $6^{\text {th }}$ graders of "Central Area Middle School". In January, the mentors are split into four different groups, and they begin to practice in these groups for the delivery of the intervention in February. Each group is led by one or two mentor facilitators, but the mentors are the main participants in the delivery of the intervention, which runs for an hour and fifteen minutes. The intervention itself consists of an introductory skit portraying the four types of bullying behavior (verbal, physical, relational, and cyber - as defined earlier), a skit that portrays how to be an empowered bystander, and other participatory activities such as an informal survey and small group discussions. The CASS officers (president, vice president, secretary, and treasurer) act as the group facilitators, while the other mentors play key parts in the intervention as well, acting as the "bullies" and the "empowered bystanders" in the skits, and lead the small group activity.

\section{Purpose and Rationale}

The purpose of the $6^{\text {th }}$ grade intervention program, like the purpose of the CASS program in general, is to prevent bullying from occurring. By targeting children before they enter middle school, and by using peers as mentors/educators, it is hoped that when the students come to the middle school, they will remember the intervention program and the CASS mentors, and therefore look to them as models, as those who aren't perpetrators of bullying, as described earlier in relation to social learning theory. In turn, the goal of this is to create a safe school.

Another main goal of the intervention program that is perhaps less obvious but just as, if not more, important than preventing the $6^{\text {th }}$ graders from becoming bullies themselves when they enter middle school, is teaching them how to become empowered bystanders. Too often, bystanders "behave in ways that assist, encourage, or allow school bullying...because they do not know what it is they should do" to stop bullying (as cited in Oh \& Hazler, 2009, p. 293). The 
CASS program adheres to the belief that "bystanders' potential for breaking the cycles of school bullying is substantial," (p. 293) and thus the intervention program aims to equip the $6^{\text {th }}$ graders with knowledge of what to do when they witness bullying, including standing up to the bully, befriending the victim, and most importantly, telling a staff member or school official.

CASS combines two complementary, research based bullying prevention programs, and uses peer mentors, who have proven to be quite effective in altering people's views, as indicated by the research cited above. CASS' success has been impressive and has proved to be an effective bullying prevention program for "Central Middle School." As a result, it would be advantageous for this model to replicated in other school systems as a potential means to prevent and address bullying.

\section{Summary}

\section{SUMMARY}

The purpose of this research was to review the existing literature on bullying, including its prevalence and its impact on those involved, to examine the importance of peers and the rationale for using peers as educators, and to explore a number of existing bullying prevention programs. This research also sought to describe and evaluate the bullying prevention program, Creating a Safe School, which is in place at a local middle school in Central Pennsylvania: "Central Area Middle School".

\section{CONCLUSION}

Although rates of bullying vary depending on how it is defined and measured, its presence in and impact on adolescents' lives is undeniable. There are numerous types of bullying, including physical, verbal, social, psychological, and cyberbullying (Carr-Gregg \& Manocha, 2011), and though boys tend to engage more in physical bullying and girls more in social and psychological, both genders can be perpetrators of any or multiple kinds of bullying (Crick, Bigbee, \& Howes, 1996). Though people assume that bullying has a negative impact only on the victims, several studies have found that the perpetrators of bullying suffer, as well. Perpetrators often have more trouble in school, lack supportive friends and befriend other perpetrators of bullying instead (Pepler, Craig, Jiang, \& Connolly, 2008), and are involved with several "problem behaviors" (Haynie et al., 2001, p. 44). Being a victim of bullying is related to more "psychosocial problems," (Nishina, Juvonen, \& Witikow, 2005, p. 43) leading to lower levels of school functioning, and is also related to "poorer social and emotional adjustment [including] greater difficulty making friends...and greater loneliness" (Nansel et al., 2001, p. 2098).

Because of the negative effects associated with bullying, there are numerous prevention programs in existence. The largest is Olweus' Bullying Prevention Program, which has been implemented in several schools with varying levels of success (Olweus, 1993; Bauman, 2008). Other programs, modeled after Olweus' program, have been implemented in schools as well, and have reported increased awareness of bullying behaviors and reduced involvement in such behaviors (Meraviglia et al., 2003; Bauman, 2008). Smith, Cousins, \& Stewart (2005), in an effort to define what contributes to a prevention program's success, concluded that antibullying programs "can yield valuable returns by helping to create school environments that are safer and more peaceful for children, and, by implication, more conducive for learning and healthy development" (p. 753).

One specific bullying prevention program used at "Central Area Middle School", located in central Pennsylvania, is the Creating a Safe School (CASS) program. The program is led by the guidance counselor of the school, and it utilizes students themselves as peer mentors. This 
peer mentor component is what makes the program unique. Peer mentors deliver an intervention program to the sixth-graders aimed at increasing their awareness of bullying and empowering them as bystanders. The program incorporates parts of both the Ophelia Project, which targets mainly relational aggression, and the Bully Free Program (Beane, 2009), which is a broader program aimed at preventing other forms of bullying and at empowering bystanders. The two programs combined presumably form a more comprehensive program, as each complements and fulfills what the other lacks. As a result, CASS has been well received and is believed to be quite effective for the prevention and responses to bullying behaviors.

\section{IMPLICATIONS AND RECOMMENDATIONS}

Because bullying is such a common occurrence and has so many negative implications for those involved, there is great need for prevention programs in every school, at every level. Although there are several prevention programs in existence, the research seems to be inconclusive when it comes to determining what exactly are the most effective components of each program, as success generally varies from study to study and school to school. Future research is needed to develop prevention programs that potentially combine aspects of programs already in existence. Further evaluation and examination of these programs in schools all over the United States must also be conducted in an attempt to prove their effectiveness regardless of location. Researchers should also gather quantitative and qualitative data to determine the effectiveness of such programs. The effectiveness of the CASS program is quite positive. Because CASS utilizes several features of two programs, that have proven effectiveness, as well as an intervention program, something which is lacking from most other prevention programs, there is reason to believe that the program is worthwhile, and thus should serve as a model for future programs in other schools.

\section{References}

Bauman, S. (2008). The role of elementary school counselors in reducing school bullying. The Elementary School Journal, 108(5), 362-375.

Beane, A.L. (2009). Bullying prevention for schools: A step-by-step guide to implementing a successful anti-bullying program. San Francisco, CA: Jossey-Bass.

Bully Free Systems $@$. (2012). Description of the bully free program. Retrieved from http://www.bullyfree.com/bully-free-program/description-of-the-bully-free-program.

Carr-Gregg, M., \& Manocha, R. (2011). Bullying: Effects, prevalence and strategies for detection. Adolescent Health, 40(3), 98-102.

Crick, N.R., \& Grotpeter, J.K. (1995). Relational aggression, gender, and social-psychological adjustment. Child Development, 66(3), 710-722.

Crick, N.R., Bigbee, M.A., \& Howes, C. (1996). Gender differences in children's normative beliefs about aggression: How do I hurt thee? Let me count the ways. Child Development, 67(3), 1003-1014.

Erikson, E. (1963). Childhood and society. New York: W.W. Norton \& Company.

Glew, G.M., Fan, M., Katon, W., Rivara, F.P., \& Kernic, M.A. (2005). Bullying, psychosocial adjustment, and academic performance in elementary school. Archives of pediatrics and Adolesent Medicine, 159(11), 1026-1031.

Guerra, N.G., Williams, K.R., \& Sadek, S. (2011). Understanding bullying and victimization during childhood and adolescence: A mixed methods study. Child Development, 82(1), 295-310.

Haynie, D.L., Nansel, T., Eitel, P., Crump, A.D., Saylor, K., Yu, K., \& Simons-Morton, B. (2001). Bullies, victims, and bully/victims: Distinct groups of at-risk youth. The Journal of Early Adolescence, 21(1), 29-49.

Juvonen, J., Nishina, A., \& Graham, S. (2000). Peer harassment, psychological adjustment, and school functioning in early adolescence. Journal of Educational Psychology, 92(2), 349-359.

Mellanby, A.R., Rees, J.B., \& Tripp, J.H. (2000). Peer-led and adult-led school health education: A critical review of available comparative research. Health Education Research, 15(5), 533-545. 
Meraviglia, M.G., Becker, H., Rosenbluth, B., Sanchez, E., \& Robertson, T. (2003). The expect respect project: Creating a positive elementary school climate. Journal of Interpersonal Violence, 18(11), 1347-1360.

Mitchell, K.J., Wolak, J., \& Finkelhor, D. (2007). Trends in youth reports of sexual solicitations, harassment and unwanted exposure to pornography on the internet. Journal of Adolescent Health, 40(2), 116-126.

Mynard, H., \& Joseph, S. (1997). Bully/victim problems and their assocation with Eysenck's personality dimensions in 8 to 13 year-olds. British Journal of Educational Psychology, 67(1), 51-54.

Nansel, T.R., Overpeck, M., Pilla, R.S., Ruan, W.J., Simons-Morton, B., \& Scheidt, P. (2001). Bullying behaviors among US youth: Prevalence and association with psychosocial adjustment. JAMA: Journal of the American Medical Association, 285(16), 2094-2100.

Newman, B.M., Lohman, B.J., \& Newman, P.R. (2007). Peer group membership and a sense of belonging: Their relationship to adolescent behavior problems. Adolescence, 42(166), 241-263.

Nishina, A., Juvonen, J., \& Witkow, M.R. (2005). Sticks and stones may break my bones, but names will make me feel sick: The psychosocial, somatic, and scholastic consequences of peer harassment. Journal of Clinical Child \& Adolescent Psychology, 34(1), 37-48.

Oh, I. \& Hazler, R.J. (2009). Contributions of personal and situational factors to bystanders' reactions to school bullying. School Psychology International, 30(3), 291-310.

Olweus, D. (1993). Bullying at school: What we know and what we can do. Cambridge, MA: Blackwell.

Olewus, D. (1995). Bullying or peer abuse at school: Facts and intervention. Current Directions in Psychological Science, 4(6), 196-200.

Pepler, D., Craig, W., Jiang, D., \& Connolly, J. (2008). Developmental trajectories of bullying and associated factors. Child Development 79(2), 325-338.

Seals, D., \& Young, J. (2003). Bullying and victimization: Prevalence and relationship to gender, grade level, ethnicity, self-esteem, and depression. Adolescence, 38(152), 735-747.

Simmons, R. (2011). Odd girl out. New York: Mariner Books.

Smith, J.D., Cousins, J.B., \& Stewart, R. (2005). Antibullying interventions in schools: Ingredients of effective programs. Canadian Journal of Education, 28(4), 739-762.

The Ophelia Project ${ }^{\circ}$. (2006). Who we are. Retrieved from http://www.opheliaproject.org/main/who_we_are.htm.

Turner, G., \& Shepherd, J. (1999). A method in search of a theory: Peer education and health promotion. Health Education Research, 14(2), 235-247.

WiredKids, Inc. (n.d.). What is cyberbullying, exactly? Retrieved from http://www.stopcyberbullying.org/what_is_cyberbullying_exactly.html. 